\title{
Some Statistics of Daily Rainfall Occurrence for the Canadian Prairie Provinces ${ }^{1}$
}

\author{
J. W. Hopkins AND P. RoBILlaRd \\ National Research Council, Ollarera, Canada \\ (Manuscript received 16 April 1964, in revised form 1 July 1964)
}

\begin{abstract}
ABS'RACT
A two-state Markov chain model provided very serviceable approximations to the April-September frequency statistics for duration of dry spells recorded in 45 years' observations at Edmonton, Swift Current and Winnipeg. It was less satisfactory in respect of the total number of rainy days per month, tending to underestimate the frequency of months with few rainy days. There was a minor degree of correlation in the numbers of rainy days recorded during the same month at these three locations, but no significant statistical association in those for successive months at the same location.
\end{abstract}

\section{Introduction}

Certain features of the occurrence pattern of rainy days over a 17-year period at Tel Aviv and over a 10-year period at Denver have recently been shown to be closely approximated statistically by simple Markov chain expectations (Gabriel and Neumann, 1962; Caskey, 1963). We report below an examination from this viewpoint of 45 years' data for the six months April to September of the growing season in the plains area of the Canadian Prairie Provinces.

\section{Data}

Data were recorded occurrences of days with 0.01 inch or more of rain during April-September 1916-60 at Edmonton, Swift Current and Winnipeg, extracted from the Monthly Record published by the Meteorological Branch, Canada Department of Transport. Edmonton $\left(53^{\circ} 34^{\prime} \mathrm{N}, 110^{\circ} 54^{\prime} \mathrm{W}, 2219 \mathrm{ft}\right)$ is situated in the poplar-aspen parkland region of Alberta, Swift Current $\left(50^{\circ} 17^{\prime} \mathrm{N}, 107^{\circ} 45^{\prime} \mathrm{N}, 2440 \mathrm{ft}\right)$ in the short-grass prairie region of Saskatchewan and Winnipeg $\left(49^{\circ} 54^{\prime} \mathrm{N}\right.$, $97^{\circ} 14^{\prime} \mathrm{W}, 786 \mathrm{ft}$ ) in the Manitoba lowland. Swift Current is about $250 \mathrm{mi}$ south-east of Edmonton, and Winnipeg some $350 \mathrm{mi}$ east of Swift Current.

\section{Frequency statistics}

Proportional frequencies. Table 1 lists proportional frequencies of rainy days; i.e., ratios of recorded numbers of rainy days to total numbers of days observed. These are shown for the aggregate of all rainy days and also separately for rainy days following one or two previous rainy or dry days. All were computed from the 45-year record for each month and station.

At all three locations the summer maximum frequency of rain was recorded in June. Events on successive days

\footnotetext{
${ }^{1}$ To be issued by National Research Council of Canada.
}

were clearly statistically dependent, the proportion of rainy days being consistently higher immediately after a rainy $(R / R)$ than after a dry day $(R / D)$. However the extent of this dependence, as indicated by the disparity of these two frequency ratios, was noticeably. less in mid-summer than in April, May and September. Moreover the proportion of succeeding rainy days after a rainy day was predominantly higher when the second preceding day was dry $(R / D R)$ than when it was rainy $(R / R R)$; conversely after a dry day, the proportion of succeeding rainy days was predoninantly lower when the second preceding day was also dry $(R / D D)$ than when it was rainy $(R / R \dot{D})$.

Correlations. Notwithstanding the distance separating them, rain did not occur entirely independently at these three stations. Product moment coefficients of correlation in annual fluctuations in the number of rainy days recorded at Edmonton and Swift Current averaged $r=0.33$ for the six months in question; for Swift Current and Winnipeg, and for Edmonton and Winnipeg, the corresponding averages were $r=0.30$ and $r=0.27$. All of these exceeded the 1 per cent level of statistical significance, here $r= \pm 0.16$. Covariation in the number of rainy days recorded in successive mon ths was negligible, the pooled product moment correlation coefficients for the three stations being $r=-0.12$ for April and May, $r=0.04$ for June and July, and $r=0.12$ for August and September. None of these approached its 5 per cent significance level of \pm 0.18 .

Variance. The statistical index of dispersion $\chi^{2}$ for the recorded annual frequencies of $R / D D$, or $R / R D$ etc. over the 45-yr period was computed for each month and station and compared with its expectation (Haldane, 1945) for simple random fluctuations associated with fixed underlying probabilities. The $\chi^{2}$ for $R / D R$ and for $R / R D$ agreed closely with these random expectations, both individually and collectively: On the whole, however those for $R / D D$ were significantly larger 
TABLE 1. Aggregate and conditional proportional frequencies of rainy days by month and station.

\begin{tabular}{|c|c|c|c|c|c|c|c|}
\hline Relative frequency & Station & Apr. & May & June & July & Aug. & Sept. \\
\hline Aggregate $R$ (rainy) & $\begin{array}{l}\text { Edmonton } \\
\text { Swift Current } \\
\text { Winnipeg }\end{array}$ & $\begin{array}{l}0.24 \\
0.26 \\
0.25\end{array}$ & $\begin{array}{l}0.28 \\
0.28 \\
0.27\end{array}$ & $\begin{array}{l}0.41 \\
0.38 \\
0.36\end{array}$ & $\begin{array}{l}0.40 \\
0.28 \\
0.31\end{array}$ & $\begin{array}{l}0.37 \\
0.26 \\
0.30\end{array}$ & $\begin{array}{l}0.28 \\
0.23 \\
0.31\end{array}$ \\
\hline$R / D$ (rainy after dry) & $\begin{array}{l}\text { Edmonton } \\
\text { Swift Current } \\
\text { Winnipeg }\end{array}$ & $\begin{array}{l}0.20 \\
0.21 \\
0.21\end{array}$ & $\begin{array}{l}0.23 \\
0.22 \\
0.25\end{array}$ & $\begin{array}{l}0.37 \\
0.33 \\
0.36\end{array}$ & $\begin{array}{l}0.35 \\
0.26 \\
0.31\end{array}$ & $\begin{array}{l}0.33 \\
0.22 \\
0.29\end{array}$ & $\begin{array}{l}0.23 \\
0.19 \\
0.28\end{array}$ \\
\hline$R / D D$ (rainy after dry-dry) & $\begin{array}{l}\text { Edmonton } \\
\text { Swift Current } \\
\text { Winnipeg }\end{array}$ & $\begin{array}{l}0.19 \\
0.20 \\
0.21\end{array}$ & $\begin{array}{l}0.22 \\
0.22 \\
0.24\end{array}$ & $\begin{array}{l}0.36 \\
0.33 \\
0.34\end{array}$ & $\begin{array}{l}0.34 \\
0.26 \\
0.31\end{array}$ & $\begin{array}{l}0.33 \\
0.22 \\
0.29\end{array}$ & $\begin{array}{l}0.22 \\
0.18 \\
0.26\end{array}$ \\
\hline$R / R D$ (rainy after rainy-dry) & $\begin{array}{l}\text { Edmonton } \\
\text { Swift Current } \\
\text { Winnipeg }\end{array}$ & $\begin{array}{l}0.24 \\
0.22 \\
0.22\end{array}$ & $\begin{array}{l}0.27 \\
0.24 \\
0.28\end{array}$ & $\begin{array}{l}0.38 \\
0.34 \\
0.40\end{array}$ & $\begin{array}{l}0.37 \\
0.27 \\
0.30\end{array}$ & $\begin{array}{l}0.34 \\
0.23 \\
0.31\end{array}$ & $\begin{array}{l}0.26 \\
0.25 \\
0.30\end{array}$ \\
\hline$R / R$ (rainy after rainy) & $\begin{array}{l}\text { Edmonton } \\
\text { Swift Current } \\
\text { Winnipeg }\end{array}$ & $\begin{array}{l}0.44 \\
0.44 \\
0.41\end{array}$ & $\begin{array}{l}0.46 \\
0.48 \\
0.39\end{array}$ & $\begin{array}{l}0.53 \\
0.51 \\
0.43\end{array}$ & $\begin{array}{l}0.52 \\
0.38 \\
0.38\end{array}$ & $\begin{array}{l}0.50 \\
0.42 \\
0.41\end{array}$ & $\begin{array}{l}0.46 \\
0.42 \\
0.44\end{array}$ \\
\hline$R / D R$ (rainy after dry-rainy) & $\begin{array}{l}\text { Edmonton } \\
\text { Swift Current } \\
\text { Winnipeg }\end{array}$ & $\begin{array}{l}0.49 \\
0.48 \\
0.46\end{array}$ & $\begin{array}{l}0.49 \\
0.50 \\
0.41\end{array}$ & $\begin{array}{l}0.54 \\
0.50 \\
0.44\end{array}$ & $\begin{array}{l}0.54 \\
0.43 \\
0.38\end{array}$ & $\begin{array}{l}0.57 \\
0.43 \\
0.45\end{array}$ & $\begin{array}{l}0.51 \\
0.40 \\
0.43\end{array}$ \\
\hline$R / R R$ (rainy after rainy rainy) & $\begin{array}{l}\text { Edmonton } \\
\text { Swift Current } \\
\text { Winnipeg }\end{array}$ & $\begin{array}{l}0.38 \\
0.40 \\
0.36\end{array}$ & $\begin{array}{l}0.44 \\
0.45 \\
0.36\end{array}$ & $\begin{array}{l}0.52 \\
0.51 \\
0.43\end{array}$ & $\begin{array}{l}0.51 \\
0.30 \\
0.37\end{array}$ & $\begin{array}{l}0.43 \\
0.41 \\
0.34\end{array}$ & $\begin{array}{l}0.40 \\
0.45 \\
0.46\end{array}$ \\
\hline
\end{tabular}

while those for $R / R R$ fell below. Aggregate three-station six-month (810 station-month) ratios of actual to expected $\chi^{2}$ were:

$\begin{array}{llll}R / D D & R / D R & R / R D & R / R R \\ 124 \% & 105 \% & 105 \% & 88 \%\end{array}$

\section{Markov chain approximations}

Rainy days per month. If occurrences of rainy and dry days constituted a two-state ergodic Markov chain the expectation $\kappa_{1}(z)$, variance $\kappa_{2}(z)$, and third moment $\kappa_{3}(z)$ of the frequency distribution of the number $z$ of rainy days in a total of $n$ successive days would be (Gabriel, 1959):

$\kappa_{1}(z)=n P_{R}$,

$\kappa_{2}(z)=P_{R}\left(1-P_{R}\right)\left[n(1+d) f-2 d f^{2}\left(1-d^{n}\right)\right]$

$\kappa_{3}(z)=P_{R}\left(1-P_{R}\right)\left(1-2 P_{R}\right)\left[n\left\{1+6 d f^{2}\left(1+d^{n}\right)\right\}\right.$ $\left.-6 d(1+d) f^{3}\left(1-d^{n}\right)\right]$

where $P_{R}=p_{R / D} /(1-d), d=\left(p_{R / R}-p_{R / D}\right), f=1 /(1-d)$

and $p_{R / D}$ and $p_{R / R}$ are the transition probabilities of rainy after dry and of rainy after rainy days, respectively.

If $p_{R / D}$ and $p_{R / R}$ for any specified month and station are assumed constant, maximum likelihood estimates $\hat{p}_{R / D}$ and $\hat{p}_{R / R}$ of them are provided by the corresponding observed proportional frequencies of $R / D$ and of $R / R$. These $\hat{p}_{R / D}$ and $\hat{p}_{R / R}$ may then be substituted for $p_{R / R}$ and $p_{R / R}$ in the foregoing Markov formulae to deduce estimates $\hat{\kappa}_{1}(z)$ of the mean, $\left[\kappa_{2}(z)\right]^{\frac{1}{2}}$ of the standard deviation and $\hat{\gamma}_{1}(z)=\hat{\kappa}_{3}(z) /\left[\hat{\kappa}_{2}(z)\right]^{\frac{3}{2}}$ of the skewness of $z$. When $\hat{\kappa}_{1}(z),\left[\kappa_{2}(z)\right]^{\frac{3}{2}}$ and $\gamma_{1}(z)$ calculated in this way and averaged over the eight instances with $\hat{d}=\left(\hat{p}_{R / R}-\hat{p}_{R / D}\right)>0.20$ and over the 10 instances with $\hat{d}<0.20$ were compared with the corresponding $k_{1}(z)$, $\left[k_{2}(z)\right]^{\frac{1}{2}}$ and $g_{1}(z)$ calculated from the sample cumulants of actually recorded $z$, the results were:

$\begin{array}{lcc}\text { Statistic } & \hat{d}>0.20 & \hat{d}<0.20 \\ \text { Mean: } & & \\ \text { Actual } k_{1} & 7.9 & 10.3 \\ \text { Markov } \hat{\kappa}_{1} & 8.4 & 11.1 \\ \text { Standard deviation: } & & \\ \text { Actual }\left(k_{2}\right)^{\frac{1}{2}} & 3.2 & 3.0 \\ \text { Markov }\left(\hat{\kappa}_{2}\right)^{\frac{1}{2}} & 3.1 & 3.0 \\ \text { Skewness: } & & \\ \text { Actual } g_{1} & 0.34 & 0.02 \\ \text { Markov } \hat{\gamma}_{1} & 0.29 & 0.14\end{array}$

On the average the observed and calculated standard deviation and skewness agreed closely, but the mean value of $z$ was slightly, but consistently, over-estimated by $n \hat{p}_{R / D} /(1-\hat{d})$. The Markov chain frequency formula (Gabriel and Neumann, 1962, Eq (12)) accordingly tended to underestimate the number of months with few rainy days, as illustrated in Table 2.

Dry spells. Dry spells, that is sequences of dry days between rainy days, may have large effects on prairie agriculture. For a Markov chain the proportional frequency of such spells of length $x>1$ would be given by $p_{R / D}\left(1-p_{R / D}\right)^{x-1}$. The distribution of $x$ would then be that of binomial waiting times, namely geometric (Wilks, 1962) with mean $\kappa_{1}(x)=1 / p_{R / D}$ and standard deviation $\left[\kappa_{2}(x)\right]^{\frac{1}{2}}=\left(1-p_{R / D}\right)^{\frac{1}{2}} / p_{R / D}$. On substitution as before of $\hat{p}_{R / D}$ for $p_{R / D}$, the following average con- 
TABLE 2. Actual $(f)$ and calculated Markov chain $(\phi)$ frequency $1916-60$ of $z$ or fewer rainy days per month.

\begin{tabular}{rrrrr}
\hline & \multicolumn{2}{c}{ April, Winnipeg } & \multicolumn{2}{c}{ July, Edmonton } \\
$z$, days & $f$ & $\phi$ & $f$ & $\phi$ \\
\hline 4 or fewer & 7 & 5.5 & 0 & 0.1 \\
7 or fewer & 26 & 21.2 & 1 & 1.8 \\
10 or fewer & 39 & 36.7 & 15 & 9.8 \\
13 or fewer & 43 & 43.4 & 30 & 25.1 \\
16 or fewer & 45 & 44.8 & 41 & 38.4 \\
19 or fewer & 45 & 44.9 & 44 & 43.9 \\
22 or fewer & 45 & 45.0 & 45 & 44.9 \\
25 or fewer & 45 & 45.0 & 45 & 45.0 \\
& & & & \\
\hline
\end{tabular}

trasts of actual and expected values of these statistics were obtained. (To reduce truncation bias in these comparisons, recorded dry spells extending from one month into the next were credited wholly to the month containing the greater part of their length.)

$\begin{array}{lcc}\text { Statistic } & \hat{d}>0.20 & \hat{d}<0.20 \\ \text { Mean : } & & \\ \text { Actual } k_{1} & 4.69 & 3.23 \\ \text { Geometric } \kappa_{1} & 4.70 & 3.24 \\ \text { Standard deviation : } & & \\ \text { Actual }\left(k_{2}\right)^{\frac{1}{2}} & 4.48 & 2.76 \\ \text { Geometric }\left(\hat{\kappa}_{2}\right)^{\frac{1}{2}} & 4.13 & 2.70\end{array}$

Over the 10 cases with $\hat{d}<0.20$ the averages of actual and calculated means and standard deviations were in excellent agreement. Over the eight cases with $d>0.20$ the means were also very similar but the actual standard deviations were on the average about 8 per cent greater than those calculated. Two illustrative examples of actual and geometric frequencies are given in Table 3. The first of these is the more representative of the agreement in general, while the results for September at Swift Current are the most discrepant of the 18 instances considered. (Detailed results are available on request).

\section{Discussion}

The Markov chain model oversimplifies the prairie climatological situation in two respects. Firstly, the trends in transition probabilities generating the observed seasonal precipitation pattern must actually occur continuously rather than by discrete monthly steps. In reality therefore the system must be nonstationary even within months. Secondly, in spring and summer convectional effects augment and supplement frontal precipitation to an extent varying progressively with the season as the land becomes heated (Kendrew and Currie, 1955) and resulting in a changing mixture of operative transition probabilities. These circumstances are reflected statistically in the seasonal trend and departures from first-order dependence of the recorded frequency ratios listed in Table 1 , and in the $\chi^{2}$ indications of departures from simple random variance. On balance they have resulted in less per-
TABLE 3. Actual $(f)$ and calculated geometric $(\phi)$ frequency 1916-60 of dry spells of $x$ or more days duration.

\begin{tabular}{lrrrr}
\hline & \multicolumn{3}{c}{ June, Swift Current } & \multicolumn{2}{c}{ Sept, Swift Current } \\
$x$, days & \multicolumn{1}{c}{$f$} & $\phi$ & \multicolumn{1}{c}{$\boldsymbol{\phi}$} & \multicolumn{1}{c}{$\phi$} \\
\hline 1 or more & 263 & 263.0 & 192 & 192.0 \\
2 or more & 172 & 175.7 & 149 & 154.7 \\
3 or more & 114 & 117.4 & 119 & 125.1 \\
5 or more & 55 & 52.4 & 80 & 81.7 \\
7 or more & 25 & 23.4 & 52 & 53.3 \\
10 or more & 4 & 6.9 & 35 & 28.0 \\
14 or more & 1 & 1.4 & 16 & 11.4 \\
21 or more & 0 & 0.1 & 6 & 2.2 \\
28 or more & 0 & 0.0 & 4 & 0.8 \\
\hline
\end{tabular}

sistence of rainy days than would characterize Markov chain occurrences.

Predictive errors resulting from ignoring seasonal trend over short intervals, as in assuming constancy of transition probabilities within months, may not be serious; but because of their mixed frontal and convectional origin, aggregate frequencies of rainy days might perhaps be more closely representable by negative binomial compound Poisson (Feller, 1957, XII.2) than by Markov frequency formulae. When rainfall is suboptimal however dry spells are of major concern, and in the present instance indications are that very serviceable approximations to the occurrence pattern of such spells may be calculable from first-order transition proportional frequencies. Substituting these into the geometric function gives estimates of the probabilities that when today is dry, rain will next fall after a further $(x-1)$ dry days. We would expect the number of dry spells of all lengths over a period of $m$ years in a month of $n$ days to be on the average slightly overestimated by $m n \hat{P}_{R}\left(1-\hat{p}_{R / R}\right)$, and to be more closely approximated by $m n \hat{p}_{R}\left(1-\hat{p}_{R / R}\right)$, where $\hat{p}_{R}$ is the recorded aggregate relative frequency of rainy days.

Acknowledgment. Thanks are due to Mr. P. P. F. Clay for technical advice and help in IBM $1620 \mathrm{com}-$ putation programming.

\section{REFERENCES}

Caskey, J. E., Jr., 1963: A Markov chain model for the probability of precipitation occurrence in intervals of various 'length. Mon. Wea. Rev., 91, 298-301.

Feller, W., 1957: An introduction to probability theory and its applications. 2nd ed. New York, John Wiley and Sons, Inc., Chap. XII.2.

Gabriel, K. R., 1959: The clistribution of the number of successes in a sequence of dependent trials. Biometrika, 46, 454-460.

-.., and J. Neumann, 1962: A Markov chain model for daily rainfall occurrence at Tel Aviv. Quart. J. R. meteor. Soc., 88, 90-95.

Haldane, J. B. S., 1945: The use of $\chi^{2}$ as a test of homogeneity in a $(n \times 2)$-fold table when expectations are small. Biometrika, 33, 234-238.

Kendrew, W. G., and B. W. Currie, 1955: The climate of central Canada. Ottawa, The Queen's Printer, 43-52.

Wilks, S. S., 1962 : Mathematical statistics. New York, John Wiley and Sons, Inc., 143-144. 